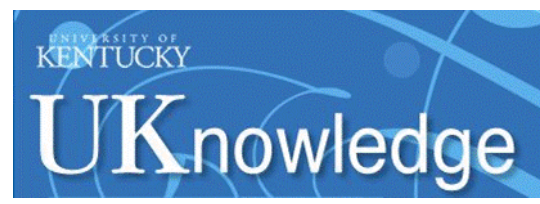

University of Kentucky

UKnowledge

$10-1-2016$

\title{
Improving a Dental School's Clinic Operations Using Lean Process Improvement
}

\author{
Fonda G. Robinson \\ University of Kentucky \\ Larry L. Cunningham \\ University of Kentucky, Ilcunn2@uky.edu \\ Sharon P. Turner \\ University of Kentucky \\ John E. Lindroth \\ University of Kentucky, jlind1@pop.uky.edu \\ Deborah Ray \\ University of Kentucky, deborah.ray@uky.edu
}

See next page for additional authors

Follow this and additional works at: https://uknowledge.uky.edu/ohp_facpub

Part of the Dentistry Commons

Right click to open a feedback form in a new tab to let us know how this document benefits you.

\section{Repository Citation}

Robinson, Fonda G.; Cunningham, Larry L.; Turner, Sharon P.; Lindroth, John E.; Ray, Deborah; Khan, Talib; and Yates, Audrey, "Improving a Dental School's Clinic Operations Using Lean Process Improvement" (2016). Oral Health Practice Faculty Publications. 5.

https://uknowledge.uky.edu/ohp_facpub/5

This Article is brought to you for free and open access by the Oral Health Practice at UKnowledge. It has been accepted for inclusion in Oral Health Practice Faculty Publications by an authorized administrator of UKnowledge. For more information, please contact UKnowledge@lsv.uky.edu. 


\section{Improving a Dental School's Clinic Operations Using Lean Process Improvement}

\section{Notes/Citation Information}

Published in Journal of Dental Education, v. 80, no. 10, p. 1170-1179.

Reprinted by permission of Journal of Dental Education, Volume 80, 10 (October 2016). Copyright 2016 by the American Dental Education Association. http://www.jdentaled.org

\section{Authors}

Fonda G. Robinson, Larry L. Cunningham, Sharon P. Turner, John E. Lindroth, Deborah Ray, Talib Khan, and Audrey Yates 


\title{
Improving a Dental School's Clinic Operations Using Lean Process Improvement
}

\author{
Fonda G. Robinson, DMD; Larry L. Cunningham, DDS, MD; Sharon P. Turner, DDS, JD; \\ John Lindroth, DDS; Deborah Ray, DMD; Talib Khan, BDS, MHA, LSSBB; \\ Audrey Yates, BS, MS
}

Abstract: The term "lean production," also known as "Lean," describes a process of operations management pioneered at the Toyota Motor Company that contributed significantly to the success of the company. Although developed by Toyota, the Lean process has been implemented at many other organizations, including those in health care, and should be considered by dental schools in evaluating their clinical operations. Lean combines engineering principles with operations management and improvement tools to optimize business and operating processes. One of the core concepts is relentless elimination of waste (non-valueadded components of a process). Another key concept is utilization of individuals closest to the actual work to analyze and improve the process. When the medical center of the University of Kentucky adopted the Lean process for improving clinical operations, members of the College of Dentistry trained in the process applied the techniques to improve inefficient operations at the Walk-In Dental Clinic. The purpose of this project was to reduce patients' average in-the-door-to-out-the-door time from over four hours to three hours within 90 days. Achievement of this goal was realized by streamlining patient flow and strategically relocating key phases of the process. This initiative resulted in patient benefits such as shortening average in-the-door-to-outthe-door time by over an hour, improving satisfaction by $21 \%$, and reducing negative comments by $24 \%$, as well as providing opportunity to implement the electronic health record, improving teamwork, and enhancing educational experiences for students. These benefits were achieved while maintaining high-quality patient care with zero adverse outcomes during and two years following the process improvement project.

Dr. Robinson is Associate Dean of Clinic Administration and Patient Care and Associate Professor, Division of Restorative Science and Prosthodontics, College of Dentistry, The Ohio State University; she was Associate Dean of Clinical Affairs, College of Dentistry, University of Kentucky at the time of this study; Dr. Cunningham is Interim Chair of Oral Health Science, Division Chief of Oral and Maxillofacial Surgery, and Professor, Division of Oral and Maxillofacial Surgery, College of Dentistry, University of Kentucky; Dr. Turner is Dean Emeritus and Professor, Division of Public Health Dentistry, College of Dentistry, University of Kentucky; Dr. Lindroth is Associate Professor, Division of Oral Diagnosis/Oral Medicine/Oral Radiology and Director of Urgent Care, College of Dentistry, University of Kentucky; Dr. Ray is Assistant Professor, Division of Comprehensive Care, College of Dentistry, University of Kentucky; Dr. Khan is System Director, Performance Improvement, St. Vincent's Healthcare, Jacksonville; and Ms. Yates is Lean Facilitator, UK HealthCare Center on Enterprise Quality and Safety, University of Kentucky. Direct correspondence to Dr. Fonda G. Robinson, College of Dentistry, The Ohio State University, 1130 Postle Hall \#175, 305 W. 12th Avenue, Columbus, OH 43210-1267; 614-292-6983; robinson.1490@osu.edu.

Keywords: dental education, clinic management, dental clinic, patient care management, patient satisfaction, practice management, lean production, continuous improvement

Submitted for publication 11/5/15; accepted 3/12/16

$\mathrm{T}$ The term "lean production," also known as "Lean," describes a process of operations management pioneered at Toyota Motor Company that contributed significantly to the success of the company. Although developed by Toyota, the Lean process has been used by many other organizations after being popularized in an influential text by Womack et al. ${ }^{1}$ Lean process improvement combines engineering principles with operations management and improvement tools to optimize business processes. ${ }^{2}$

There is currently a great deal of interest in improving the safety, quality, and effectiveness of health care in the U.S. ${ }^{3}$ Quality, for instance, may be defined somewhat subjectively by various constituencies in the health care arena, but always includes concerns with efficiency, appropriateness of care, patient safety, and cost-effectiveness. By its very nature, health care entails complex, multistep processes that usually involve multiple personnel, complex protocols, and sophisticated technology. Often, specialized instruments and supplies must be readily available, with variations accessible if needed. The complexity of such systems increases the chances for errors of omission or commission. Such errors endanger patient welfare and accelerate 
health care costs. It has been estimated that the health care industry wastes nearly $\$ 700$ billion annually. ${ }^{4}$

Findings from the Agency for Healthcare Research and Quality (AHRQ)'s sponsored research in this area appeared in the report Cost of Poor Quality or Waste in Integrated Delivery System Settings. ${ }^{5}$ Categories of quality waste identified in that report included overuse (as occurs when the risk of providing an intervention is greater than the risk of its potential benefit), underuse (failing to provide an effective intervention when it would benefit the patient), and misuse (harm that results from avoidable complications of appropriate interventions). All three of these quality failures represent process defects and, as such, are amenable to process improvement techniques, including the Lean process.

Analysis of quality waste provides a mechanism to identify opportunities for improvement and to apply appropriate corrective measures. The basic strategy is to determine the etiology of the failure and then modify the process to reduce the likelihood of a suboptimal outcome. Such process improvement should produce better health outcomes, reduce waste, improve quality, and/or lower health care costs.

Another type of waste is inefficiency waste. Two equally effective interventions may differ with regard to efficiency. If the two produce similar results but one consumes more resources (e.g., time, material, clinic space), then the most economical intervention would be the most efficient. Given the constraints on available health care resources, inefficient interventions or processes waste resources and thus have a negative impact on public health.

Although originally developed in the industrial sector, the Lean process improvement tools are being progressively used in service settings such as health care to optimize operations through higher efficiency. This article argues that dental schools should consider using the Lean process in evaluating their clinic operations and supports that argument by describing the process and results of the University of Kentucky College of Dentistry's adoption of the Lean process for improving operations in its Walk-In Dental Clinic.

\section{Lean Concepts Applied to Health Care}

Historical antecedents to and strong influences on the Lean process include Ford's early assembly line, the scientific management practices advocated by Frederick Taylor, and a "system of profound knowledge" as described by W. Edwards Deming. ${ }^{6-8}$ The Toyota Production System or Lean Manufacturing was introduced by Taiichi Ohno in $1945 .{ }^{9}$ The process received widespread attention due to Toyota Motor Company's success, which was largely attributed to this methodology. ${ }^{1}$

The foundation of lean process improvement is a relentless and continuous elimination of process elements that do not add value to the customers or the outcome. These elements are referred to as "waste" (muda in Japanese). The elimination of waste is combined with incorporating or strengthening those elements that enhance and add value. In his original description, Ohno identified seven types of waste to be sought out and eliminated. ${ }^{9}$ These wastes represent non-profitable actions performed by employees in an organization. Ohno's original seven wastes were the following: Transport-unnecessary movement of resources such as supplies; Inventory-amount not commensurate with that required for the operation; Motion - generally reflects poor process or facility design; Waiting - the document, workpiece, or patient is "waiting" for the next step; Overproduction - producing more than is required; Overprocessing - process steps that are unnecessary; and Defects - suboptimal results that require rework or replacement.

The elimination of waste consists of the excision of steps or processes that do not add value to the end result. This value is defined by the customer. Lean does not rely upon external experts to drive this process, but rather harnesses the expertise of workers engaged in the work. These individuals are the most familiar with the processes. The emphasis is on solving commonly occurring challenges by using a standard set of solutions, while prioritizing consumers' needs. ${ }^{9}$ Various tools and techniques used to achieve these ends are derived from certain key principles or concepts that define the Lean process. The core principles of Lean as applied to health care are 1) consumer (patient) perspective, 2) pull, 3) flow, 4) value stream, and 5) perfection, all of which underscore continuous improvement. ${ }^{10}$

The patient perspective relates to value creation and is an essential component of Lean. This principle underscores the primacy of patient values as the key driver in the process improvement cycle. Any process or activity that adds value to the patient's experience is desirable, provided that the value added is commensurate with the defined costs; everything else is waste to be eliminated or reduced. It should be noted, however, that there are constituencies other than 
patients, including practitioners, staff, and students/ residents. The needs of all of these constituencies must be taken into account, although the primacy of the patients' needs is commonly recognized in health care organizations.

Pull pertains to providing services according to the demand. This concept emphasizes the utilization of available resources to deliver care in a timely manner, not before or after care is required. In the manufacturing sector, this concept has been referred to as "just in time" production. ${ }^{9}$ Pull would prevent unnecessary queuing and downtime of human resources. Examples from a clinical perspective would be adequately staffing a clinic according to patient arrival time patterns to discourage staffing far in advance or too late and optimizing the use of a device or physical resource (e.g., a treatment room, surgical assisting staff, cone beam CT).

Flow dictates that the work piece (in health care, the patient) is receiving value at each step in the process as opposed to unproductive waiting in a dental chair or reception area with no treatment being provided. In practice, flow might be accomplished by scheduling procedures that seek to accomplish treatment in fewer appointments, since each patient encounter involves a certain amount of fixed preparation and take-down time. Flow ensures smooth transition of a process and obviates potential mistakes that could occur due to overload. Additionally, continuous flow removes the potential for excessive waiting that can occur with the batching of a process.

Value stream is a mechanism to achieve a smooth flow, creating a system wherein each step adds value to the patient experience. Value stream involves the mapping of an end-to-end process. This principle links all the steps involved in a process to assist in understanding the impact of each individual step on the preceding and subsequent ones and the overall effect on the total operation (e.g., treating a patient in the emergency department so that each timely step provides or facilitates additional careexam, radiology, re-evaluation, and treatment).

Perfection relates to continuous improvement (kaizen). Establishing a standardized process enables achievement of a clean and organized state, thereby creating the basis for continuous improvement. Once a desired state has been achieved, Lean focuses on improving the process further, eventually forming a virtuous and self-sustaining cycle wherein each new improvement acts as a guiding force for subsequent improvements (e.g., avoiding medication errors by raising awareness with staff, checking patient IDs, and placing different strengths of the same medication into different drawers). ${ }^{10}$

The goals of Lean processes are achieved through a set of process improvement tools. Some of the more commonly used Lean tools are Value Stream Mapping (VSM), A3 report, Go See, and small cycles of change. ${ }^{9}$ VSM is a technique used to map the end-to-end process. It gives a visual perception of the entire workflow process while recognizing the value-added and non-value-added activities. Mapping helps identify bottlenecks in the process (e.g., treating a patient for extended time in the emergency department). ${ }^{7} \mathrm{An} \mathrm{A} 3$ report is a singlepage problem-solving methodology that identifies the aim of the proposed project with measures that will be utilized to monitor the progress and desired state of potential change. The term "A3" derives from the size of the paper Toyota used for such reports. This report also includes names of the team members involved in the process and the impact the project would have on people, service, quality, cost, and growth (Figure 1). ${ }^{9,11}$ Go See entails actual observation of the process by going to the source directly for better understanding of how and what happens on the floor; it allows managers to visualize the process and better understand employee concerns. ${ }^{12}$ Small cycles of change involve implementing and testing a new change for a brief period of time, typically a few days, followed by evaluation of responses from stakeholders. In that way, a new process can be refined before fully implementing it in standardized work practices (e.g., reducing surgical errors by reviewing checklists prior to surgery).

\section{Applying Lean to the Dental School Clinic}

For several years, the University of Kentucky College of Dentistry's Walk-In Dental Clinic, designed for patients with urgent needs, had been described as a dysfunctional clinical operation. Patients were dissatisfied, as evidenced by negative patient satisfaction survey scores and comments. The primary complaints centered on the clinic's inefficiencies. Statements such as "I arrived at 9 am and left at $3 \mathrm{pm}$ " or "I waited in the reception area for over two hours before being seen" were among the common written comments from patients who received dental services in this setting.

In addition to patient dissatisfaction, the staff, residents, and faculty were frustrated due to the 


\section{Walk-In Clinic project}

\section{AIM: Reduce patients' door-to-door time to $\mathbf{3}$ hours within 90 days}

MEASURE:

1) Door-to-door time

2) Time interval between different procedures or phases of entire registration and treatment process

3) Patient satisfaction comments

\section{CHANGES:}

\author{
Implementation of EHR \\ Streamline patient process flow \\ Relocate phases of process to \\ other locations
}

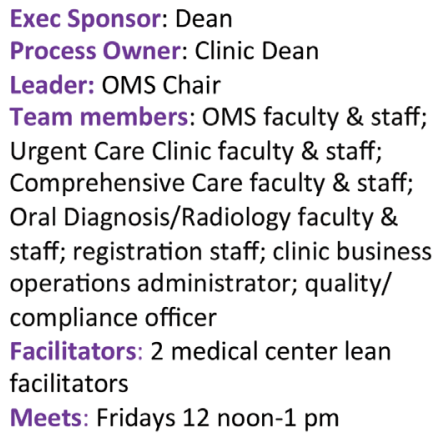

Exec Sponsor: Dean

Process Owner: Clinic Dean

Leader: OMS Chair

Team members: OMS faculty \& staff;

Urgent Care Clinic faculty \& staff;

Comprehensive Care faculty \& staff;

Oral Diagnosis/Radiology faculty \&

staff; registration staff; clinic business

operations administrator; quality/

compliance officer

Facilitators: 2 medical center lean

facilitators

Meets: Fridays 12 noon- 1 pm

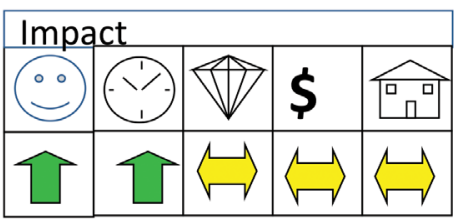

PEOPLE : Reduced complaints from patients and staff. Better planning. SERVICE: Decreased wait time. QUALITY: Afternoon clinic operates smoothly. Quality of educational experience maintained. COST: No change.

GROWTH: No change.

Figure 1. A3 (aim-measure-change) report provides a snapshot of the project

ineffectiveness of the process, which was only compounded by irate patients. Many students did not find the clinic a rewarding educational experience and often described being trapped in a chaotic system. Patient dissatisfaction and staff, faculty, and student morale were not the only issues requiring attention and improvement. The limited number and small size of triage rooms had a negative impact on patient throughput and the computer hardware required to support the electronic health record for data entry.

The Walk-In Dental Clinic was operated each morning, five days a week, by four dental students assigned to the Urgent Care Clinic and four students assigned to Oral and Maxillofacial Surgery (OMFS) Clinic rotations while supervised by faculty attendings. Patients registered in the Walk-In Dental Clinic between 7:30 am and 9:30 am and were treated on a first-come, first-served basis. A maximum of 24 patients were treated in this clinic daily. Although a variety of services were provided, the primary treatments were extractions, pulpotomy/pulpectomies, and replacement of missing/fractured restorations.
Patients registered on the first floor of the seven-floor facility and were required to pay in advance on the fifth floor in the OMFS Clinic prior to receiving services. Patients were then routed to have radiographs made in the Radiology Clinic on the first floor as part of the triage process before returning to the fifth floor. If the care plan included an extraction, services were rendered on the fifth floor. If the treatment plan included root canal therapy, the patient had to check in at the Urgent Care Clinic, on the third floor, for initiation of endodontic treatment.

Space restrictions in the OMFS Clinic did not allow for use of more than three triage rooms at any given time. The small triage area contained unacceptable barriers between rooms as they did not permit satisfactory patient confidentiality. The restricted space in the triage rooms also made use of the electronic health record impossible since they lacked space for computer equipment necessary for data entry. The afternoon OMFS surgery schedule was routinely impacted negatively by overflow of the Walk-In Dental Clinic patients. 
Overall, the Walk-In Dental Clinic thus operated on three of the seven floors in the College of Dentistry, which had an impact throughout the college. This impact was a negative influence on those working in or in close proximity to the clinic because of the disgruntled patients. It was clear that process improvement was needed for the clinic's operations.

\section{Introducing Lean to the Clinic}

The University Medical Center's Center for Quality and Safety had been educating and training clinical units throughout the clinical enterprise on the application of Lean techniques and tools for process improvement. The administration decided that the College of Dentistry's Walk-In Dental Clinic would benefit from application of Lean techniques to this clinical operation. The Center for Quality and Safety agreed to partner with the college to implement the Walk-In Dental Clinic Lean Project.

The team was comprised of 17 total members and was organized into leaders, members, and facilitators. Team leadership included the dean of the College of Dentistry as the executive sponsor, the clinic dean as the process owner, and the division chief of OMFS as the leader. Team members were selected to represent all clinic areas actively engaged with the Walk-In Dental Clinic process: OMFS faculty and staff, Urgent Care Clinic faculty and staff, comprehensive care faculty and staff, oral diagnosis/oral and maxillofacial radiology faculty and staff, registration staff, clinical business operations administrator, quality/compliance officer, and Lean facilitators. The Lean facilitators (two individuals with training in Lean management) were appointed by the Center for Quality and Safety to facilitate the project. Students and other staff members were encouraged to attend meetings to provide input and feedback as necessary. The team established regular weekly meetings for the duration of the project.

Prior to the first team meeting, each team member was expected to perform a Go See of the entire Walk-In Dental Clinic process, so that members would have better appreciation of the entire process and not just his or her contribution. The members were encouraged to ask questions when they visited other phases of the process. This aspect was vitally important in order to establish the aim or purpose of the project and was recorded on the $\mathrm{A} 3$ report.
During the first team meeting, the team decided the aim statement would be to "Reduce patients' average in-the-door-to-out-the-door time to three hours from four-plus hours, based on preliminary data, within 90 days." The team decided that as scheduled patients were allotted three hour blocks of time in the student clinics, then permitting three hours for unscheduled patients seemed a reasonable and achievable goal.

In working through the $\mathrm{A} 3$ report (Figure 1), the team decided which measures would be necessary to determine achievement of the aim based on Lean best practices. Those measures were as follows: recording in-the-door-to-out-the-door time; logging time intervals between phases of the process from registration to treatment completion; and monitoring patient satisfaction survey results. In order to standardize the time, which was critical for this project at the various locations of the Walk-In Dental Clinic process, eight large red digital clocks were purchased for this dedicated purpose. One individual synchronized the clocks on Monday morning, delivered them to each of the locations, and collected them at the weekly meeting.

Based on measures used to streamline the patient intake process, the team decided that certain changes needed to occur in order to achieve the aim. The essential changes were streamlining the patient flow process; implementing use of an electronic health record; and relocating phases of the process to other locations as patient flow, technology, and space utilization significantly impacted the patient intake process.

Following the first meeting, the facilitators met with the project leaders to review the projected impact of the aim statement and decide if the impact would be significant enough for the amount of resources that would be invested (Figure 1). There was agreement that, if the aim was achieved, not only would the quality of service improve, but by helping the OMFS afternoon clinic to operate more smoothly, productivity would potentially increase while also improving the educational experience for students. Successful achievement of the aim would not impact safety concerns. Service excellence would be improved by reducing the complaints from patients, staff, students, residents, and faculty while allowing better planning for the afternoon surgery clinics. Efficiency of staff and resource utilization would be improved by decreasing the wait time.

Lean facilitators assisted the team with VSM to determine the current state of the Walk-In Dental 


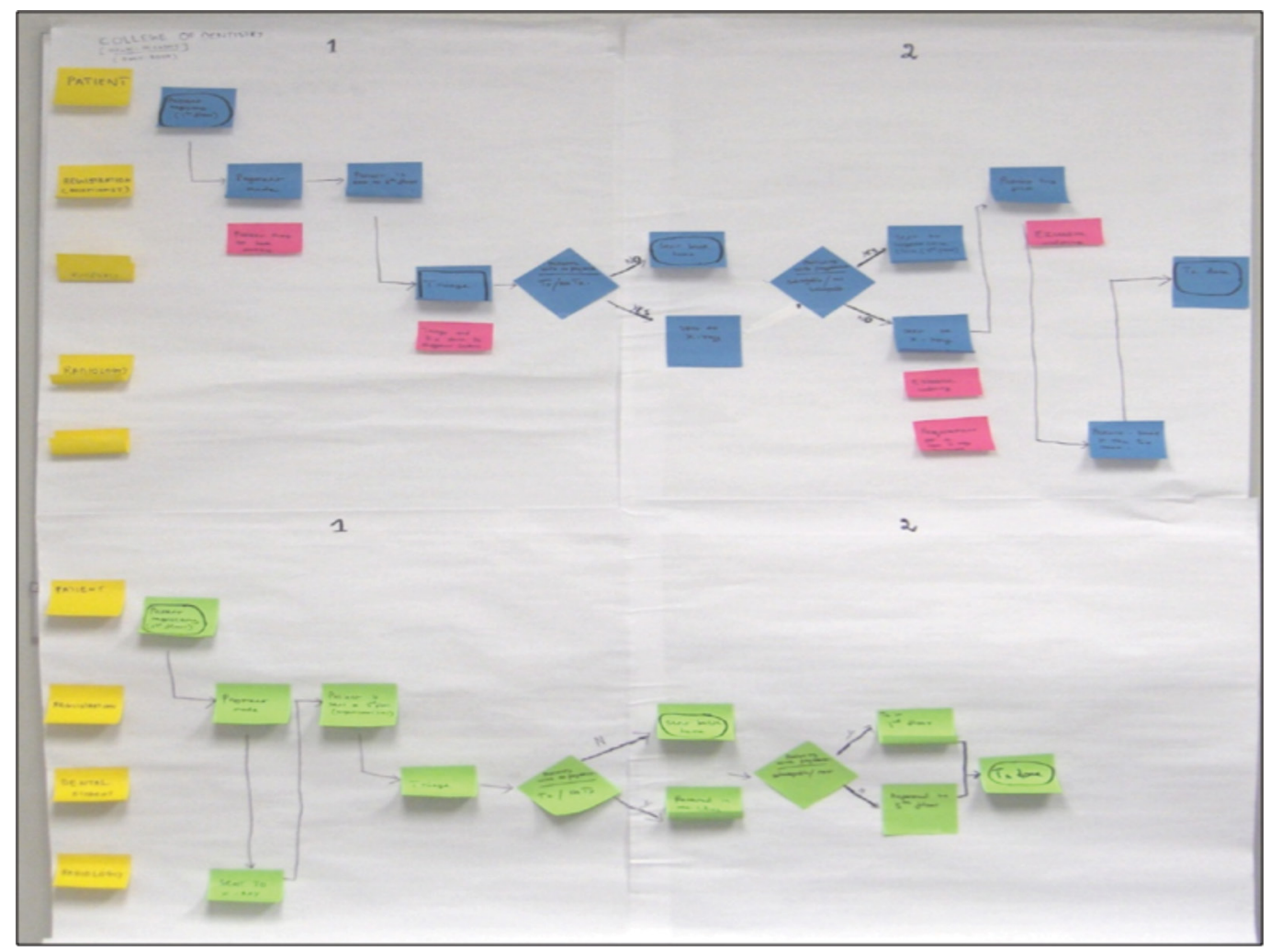

Figure 2. Value stream mapping for project

Note: Current state process steps (blue); stakeholders in the process (yellow); waste, bottlenecks, and non-value-added steps (pink); future (desired) state process steps (green).

Clinic (Figure 2). This tool allowed the team to visualize the entire end-to-end process and identify bottlenecks and waste in the process. Opportunities existed to implement small cycles of change into the process for an improved future state. The future state generally reflects fewer stakeholders and numbers of steps in the process. In this context, a small cycle of change is the process of trying something new with one patient, one dentist, one assistant (or other staff member), and one student, one time, then regrouping to determine how it worked. If it worked well, the trial time was extended to a day, then a week. If success continued, then it would become part of the process or standardized work.

Following the team's Go See of the patient registration process, the first two small cycles of change emerged (Table 1). The initial small cycle of change addressed payment location for this patient population. All new clinic patients paid at the point of patient registration on the first floor, with the exception of Walk-In Dental Clinic patients. These patients registered on the first floor but traveled to the OMFS Clinic, located on the fifth floor, to make a payment for the visit. The small cycle of change standardized the first floor patient registration area as the payment location for all new patients making payments for services.

The second small cycle of change focused on patient flow versus batching during the registration process. It was observed that all patients walked up to the registration desk, provided their driver's license and any applicable insurance cards, and then took a seat. They were later called up to the registration desk again to complete the registration process. Patients were "batched" through the registration process instead of being flowed through the process. This impacted operations as all patients were captured at the registration area, then released nearly simultaneously to enter the next phase of the process, thereby creating bottlenecks down the line. This small cycle 
Table 1. Three small cycles of change for Walk-In Dental Clinic process improvement project

\begin{tabular}{lll}
\multicolumn{2}{c}{ Small Cycle of Change Implemented } & \multicolumn{1}{c}{ Outcomes } \\
\hline 1st $\quad \begin{array}{l}\text { Collected payment at 1st floor registration } \\
\text { desk instead of 5th floor OMFS Clinic. }\end{array}$ & $\begin{array}{l}\text { Eliminated transportation waste, and improved consistency. Patients } \\
\text { were capable of registering and making payments on the same floor as } \\
\text { all other clinic patients. }\end{array}$ \\
2nd & $\begin{array}{l}\text { Flowing versus batching patients during the } \\
\text { patient registration process. }\end{array}$ & $\begin{array}{l}\text { Decreased patient wait time by decompressing bottlenecks. The reg- } \\
\text { istration process was completed for each patient, moving him or her } \\
\text { forward to the next step in the walk-in clinic process. }\end{array}$ \\
3rd & $\begin{array}{l}\text { Relocated triage and image capture from 5th } \\
\text { floor OMFS Clinic and 1st floor Radiology } \\
\begin{array}{l}\text { Clinic to 3rd floor Urgent Care Clinic (UCC). } \\
\text { Required purchase and installation of digital } \\
\text { panoramic imaging machine near UCC. }\end{array}\end{array}$ & $\begin{array}{l}\text { Decreased patient wait time. The 10-chair UCC was equipped with the } \\
\text { electronic health record (EHR) hardware/software and could easily be } \\
\text { used for triage versus the 3-chair triage area in the OMFS Clinic with- } \\
\text { out EHR capabilities. In addition, this change eliminated transportation } \\
\text { waste by providing radiology services at the point of triage in the UCC. }\end{array}$
\end{tabular}

of change established a standardized process by which a patient would complete the entire patient registration process and then be released to enter the next phase of the process. This effort attempted to minimize bottlenecks down the line.

The third small cycle of change tested triaging patients in the same location as available radiology services. Following completion of the registration process, patients were directed to the Radiology Clinic, also located on the first floor. Patients were

\section{WALK-IN CLINICPATIENT FLOW SHEET}

Please completethe information requested below as part of our process improvement project.

Date:

Chart number:

Arrival time in registration:

Time paperwork completed:

Time patient sent to $3^{\text {rd }}$ floor:

Time patient received on $3^{\text {td }}$ floor:

Time seated for triage:

Time received on $5^{\text {th }}$ floor:

Time seated for treatment:

Time treatment completed:

Figure 3. Walk-In Dental Clinic patient flow sheet to capture time interval between phases of the process triaged, and appropriate radiographs ordered and completed. The Radiology Clinic was not a long-term solution for triaging these patients, but provided a venue to test triaging patients in the same location as available radiology services.

The Urgent Care Clinic maintained ten treatment chairs with access to the electronic health record. These ten chairs were available early in the morning for triaging patients for the Walk-In Dental Clinic as opposed to the three triage chairs in the OMFS Clinic without access to the electronic health record. However, a panoramic imaging machine was not available in the vicinity. Following the transition to digital radiography near the Urgent Care Clinic, a dark room previously used for storage was available to house a panoramic imaging machine. A digital panoramic imaging machine was purchased and installed near the Urgent Care Clinic to serve the Walk-In Dental Clinic patient population. The definitive aspect of the small cycles of change was relocating the patient triage and image capture from the fifth-floor OMFS Clinic and first-floor Radiology Clinic, respectively, to the third-floor Urgent Care Clinic.

A Walk-In Dental Clinic patient flow sheet was created to record the time interval between phases of the process (Figure 3). For each patient in the process, team members in each clinical area were responsible for entering time data into the patient flow sheet. The data were collected, analyzed, and presented to the team each week by one of the Lean facilitators (Table 2).

For several years, the college had collaborated with a third party to administer, measure, and analyze the satisfaction of the patient experience. In this process, $10 \%$ of the patients treated in a given month are randomly selected and mailed a survey. A patient is mailed a survey only once in a 90 -day period. $\mathrm{Pa}$ - 


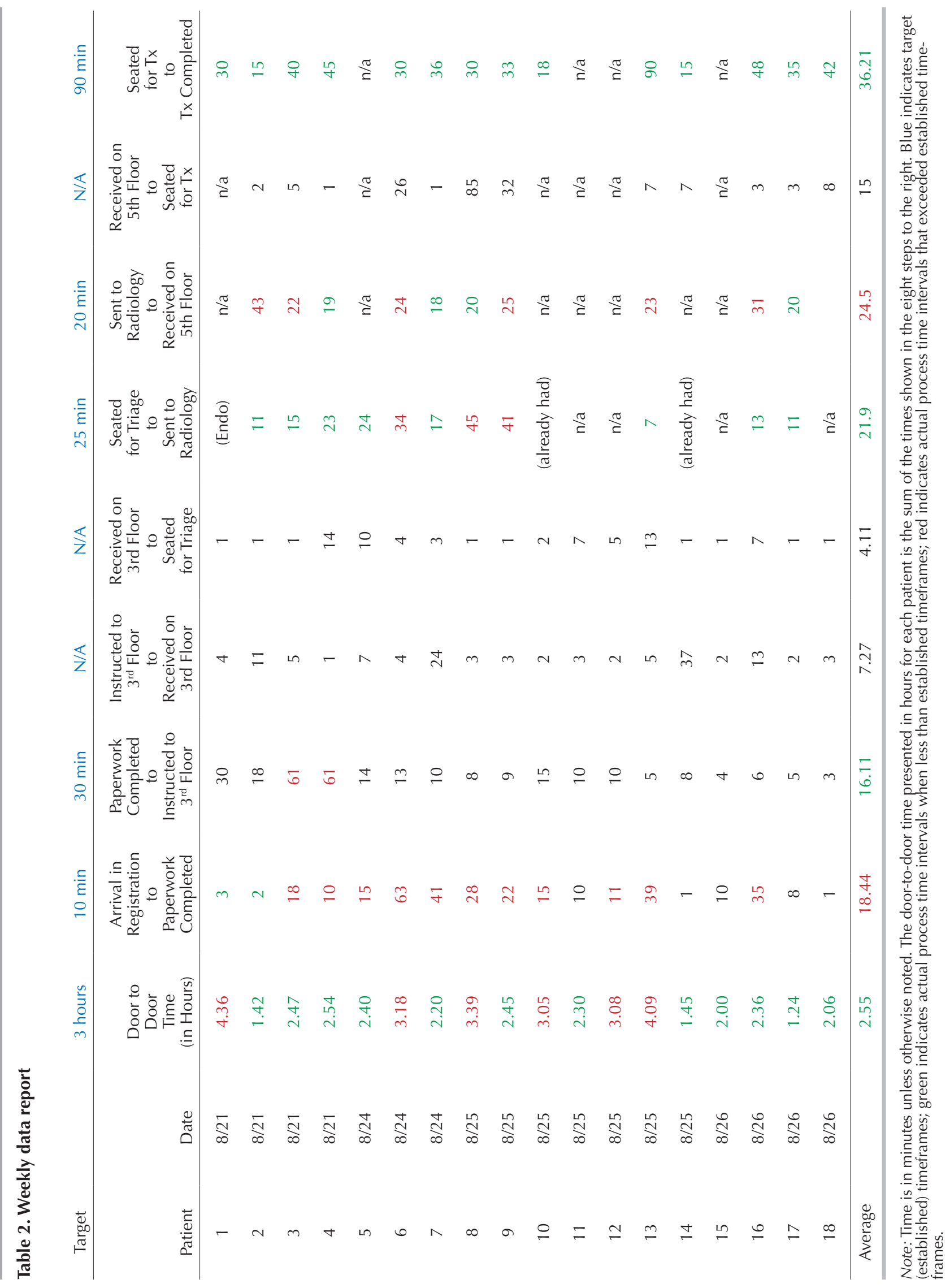


tient satisfaction data continued to be collected and analyzed through this well-established mechanism.

\section{Impact of Lean Changes}

The baseline data showed that the average door-to-door time at the onset of this project was four hours and ten minutes. The Lean project target time was three hours. After implementation of three small cycles of change (Table 1), the average door-to-door time was reduced to two hours and 54 minutes. This goal was achieved one week prior to the targeted project deadline.

During the process improvement time frame and for the next 24 months, quality outcomes were monitored via incident reporting of adverse outcomes and account adjustment request processes to ensure quality of care had not been negatively impacted with improved patient throughput in the clinic. When adverse outcomes occur, these are now reported through an internal electronic incident reporting system. Following that, a patient account adjustment request is initiated by the responsible clinic and reviewed by the compliance committee for approval. There were no increases in adverse outcomes reported from the clinic and no increases in account adjustment requests for quality or risk management purposes during this time period.

Team members discussed the results of the small cycles of change that worked well that week and reasons behind any increased time intervals. Primary causes for increased time intervals were related to the clinical management software system not being operational, which triggered the need to switch to a manual registration process or increased patient volume following holiday closure (e.g., Labor Day).

During the Walk-In Dental Clinic process improvement project and for the next 24 months, patient satisfaction and grievances were monitored. According to the patient satisfaction surveys, the overall patient satisfaction regarding care provided by this clinic improved by $21 \%$, and the number of negative comments specific to the clinic decreased by $24 \%$. There was no increase in reported patient grievances specific to the clinic during this timeframe. Although not specifically quantified, the number of complaints from the students, staff, residents, and faculty to the Office of Clinic Affairs was minimal over the same time period.

\section{Discussion}

The AHRQ and De Koning et al. have reported on the sources of inefficiency waste, which they define as "any non-value-adding work." This is essentially a Lean concept. The employees of our Walk-In Dental Clinic described a number of examples of such waste, including unnecessary redundancy (e.g., collecting the same patient information multiple times); downtime and delays (e.g., unnecessary waiting times for patients or underutilized equipment); unnecessary complexity (that did not improve outcomes); failure to deploy or use resources to improve outcomes (e.g., not consulting medical staff to obtain their input on process improvement); eliminating redundant or meaningless processes (those that should be discontinued); and consuming resources to produce products that were of little utility (e.g., management reports not used to inform the decision making process). It is possible to systematically improve processes through thoughtful experimentation, using tools such as Lean process improvement as evidenced by this clinical project. Waste is eliminated, thus adding value for all stakeholders.

The AHRQ report also addressed optimizing capacity utilization. ${ }^{5}$ For most of the service industry, there is an ideal service capacity that allows for the occasional unexpected event while ensuring that the staff are optimally employed. The issue of capacity utilization and unexpected exigencies (given the biological and psychosocial differences between patients) points to an inherent tension when translating manufacturing management practices to a health care setting. In a machining operation, round steel stock of a given dimension and composition can be expected to exhibit great similarity between individual work pieces. This, however, is not true of patients. An endodontic procedure on a maxillary first premolar may normally take a skilled endodontist 45 minutes to complete. However, if the tooth has dilacerated roots or if the patient experiences a syncopal episode, the procedure may take much longer than anticipated. Patients exhibit great variability with regard to behavioral, anatomic, and a myriad of other parameters. Thus, some excess capacity or flexible resource has to be built into health care delivery systems and most service processes to allow for the occasional unexpected turn of events.

Process improvement projects like the one described here do not exist without limitations. One 
of the most significant challenges we overcame was the incomplete data collection of the recorded time intervals onto the Walk-In Dental Clinic patient flow sheets. After several sheets were returned with incomplete information, the flow sheets were printed onto brightly colored paper, which allowed for immediate recognition of the data collection sheet. However, the facilitator spent a significant amount of time reminding students and staff to make data entries on the forms. Although there was general consensus regarding improved satisfaction among the staff, faculty, residents, and students and comments were documented in the minutes of the weekly meetings, a formal method of documenting the individual feedback would have proven beneficial. Different systems have various forces acting upon them, so similar or different benefits may be experienced as replicated in another system altogether.

Following a process improvement effort, it is critical to ensure process relapse does not occur. Periodic auditing of the process proves beneficial to counter any inclination to revert to the original process. Our process was periodically audited, once every six to eight months, for the next 24 months by the process owner to ensure the process maintained its integrity. Team members were convened when additional improvement suggestions were offered.

\section{Conclusion}

Lean is a customer-centric methodology in which every improvement effort is focused on maximizing value to the customer: in our case, this focus was primarily the patients, followed by stakeholders of the college (students, staff, and faculty). Lean establishes a common language for communication in regards to any improvement effort. It promotes a highly collaborative environment for continuously improving operations, in which people closest to the actual work are empowered to propose ideas and solutions versus a top down approach. In essence, Lean is about transforming a culture that embraces change and continuously strives for better care outcomes.
Achievement of our project's goal-reducing WalkIn Dental Clinic patients' in-the-door-to-out-the-door time from four hours and 10 minutes to three hourswas realized through streamlining patient flow and strategically relocating key phases of the process to improve care design. This improvement process resulted in shorter treatment times, improved patient satisfaction, and enhanced collaboration. Our success with this project suggests that the Lean process has applications in health care settings, including both dental and dental school clinics.

\section{REFERENCES}

1. Womack JP, Jones DT, Roos D. The machine that changed the world. New York: Rawson Associates, 1990.

2. McLaughlin DB, Hayes JM. Health care operations management. New Delhi: PHI Private Limited, 2009.

3. Porter ME, Teisberg EO. Redefining health care: creating value-based competition on results. Boston: Harvard Business School Press, 2006.

4. Graban M. Lean hospitals: improving quality, patient safety, and employee satisfaction. New York: Productivity Press, 2009.

5. Agency for Healthcare Research and Quality. Cost of poor quality or waste in integrated delivery system settings: final contract report. 2008. At: archive.ahrq.gov/research/ findings/final-reports/costpqids/index.html. Accessed 5 Nov. 2015.

6. Ford H, Crowther S. Today and tomorrow. Cambridge, MA: Productivity Press, 1926.

7. Taylor FW. The principles of scientific management. 1911. New York: Cosimo, 2006.

8. Deming WE. Out of the crisis. Cambridge: MIT Press, 1986.

9. Ohno T. Toyota production system: beyond large-scale production. New York: Productivity Press, 1988.

10. Jones D, Mitchell A. Lean thinking for the NHS. London: NHS Confederation, 2006.

11. Kuo MH, Borycki E, Kushniruk AW, Lee TS. Integrating A3 reports and the house of quality: improving workflow in the recovery room using information technology. Eur Federation Med Inform 2009;5:416-20.

12. Hoseus M, Liker JK. Servant leadership. In: Hoseus M, Liker JK, eds. Toyota culture: the heart and soul of the Toyota way. New York: McGraw Hill, 2008:317-38.

13. De Koning H, Verver JPS, Van den Heuvel J, et al. Lean six sigma in health care. J Healthcare Quality 2006; 28:4-11. 